\title{
Classical Single Factor Optimisation of Parameters for Phenolic Antioxidant Extraction from Tamarind Seed (Tamarindus indica)
}

\author{
Atreyi Sarkar and Uma Ghosh* \\ Department of Food Technology and Biochemical Engineering, Jadavpur University, Kolkata - 700032, India
}

Article history

Received: 5 June 2016

Accepted: 27 June 2016

Published: 1 July 2016

(C) Sarkar and Ghosh (2016)

Editor

K K Sabu

Publisher

Horizon e-Publishing Group

Corresponding Author

Uma Ghosh

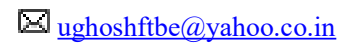

\begin{abstract}
Presently the work deals with outreaching and exhaustive investigations involving single factor optimisation method, to optimise the parameters for phenolic antioxidant extraction from the seeds of Tamarindus indica. At first the characterization of the seeds has been performed by estimating the total calorie value, carbohydrate, protein, fat, Total Polyphenol Content (TPC), moisture (\%), total ash (\%), total solid (\%), volatile solid (\%), fixed carbon (\%), bulk density (\%), $\mathrm{pH}$ and solubility. The effects of solid to solvent ratio $(1: 10-1: 30 \mathrm{w} / \mathrm{v})$, ethanol concentration $(25-100 \% \mathrm{v} / \mathrm{v})$, extraction time (1 24 hours) and extraction temperature $\left(25-60^{\circ} \mathrm{C}\right)$ have been investigated to optimise the extraction of Total Polyphenol Content (TPC) and Antioxidant capacity determined by Folin - Ciocalteu and FRAP analyses respectively. The solvent extraction conditions have been optimised at solid to solvent ratio of 1:20 w/v, 50\% ethanol as solvent and 3 hours of shaking at $40^{\circ} \mathrm{C}$.
\end{abstract}

Keywords

Optimisation; characterisation; total polyphenol content; FRAP

Sarkar, A and U. Ghosh. 2016. Classical Single Factor Optimisation of Parameters for Phenolic Antioxidant Extraction from Tamarind Seed (Tamarindus indica). Plant Science Today 3(3): 258-266. http://dx.doi.org/10.14719/pst.2016.3.3.242

\section{Introduction}

Food industries mostly utilise synthetic antioxidants to prevent oxidation of processed foods (Li et al., 2014). Though the use of synthetic additives are effective in maintaining the shelf life of processed foods, the need of substituting synthetic additives with natural antioxidants are gradually increasing day by day considering the food safety they offer (Ortiz et al., 2012; Karre et al., 2013). The biotechonomy frame and liability of modern food industries towards maintaining a sustainable environment are leading towards imposing greater emphasis on valorising food by products as a source of antioxidant in food formulations. Moreover, the fast growing population and demand for re-usable resources have triggered the use of food residues or by products as the newly emerging sources of natural antioxidants for the production of value added food. Tamarind seeds are rich sources of natural polyphenolic antioxidants (Tsuda et al., 1994; Reis et al., 2016). The fruits or pods of T. indica contains 1-10 seeds which are irregular in shape with flattened or rhomboid structure and reddish or purplish brown in colour (Akajiaku et al., 2014). The mean length, breadth and thickness of the seeds have been reported as $1.44 \pm 0.17,1.05 \pm 0.09$ \& $0.63 \pm 0.08 \mathrm{~cm}$ respectively with an average weight of $0.69 \pm 0.15 \mathrm{~g}$ per seed (Bhattacharya et al., 1991). India is a major producer of Tamarind in the world, producing 191750 tonnes of tamarind in the year 2013- 14 and the pulp of the ripe fruit is extensively 
used in Indian cuisine as a condiment (Spices Board India) generating large amount of seeds as the underutilized by-product of the tamarind pulp industry (Kumar and Bhattacharya, 2008). Though various valorisations of these seeds are possible (Sudjaroen et al., 2005), antioxidant property is presently being considered as the subject of study.

Many antioxidant compounds with high nutraceutical properties, such as 2-Hydroxy3 ', 4' - Dihydroxyacetophenone, 3,4 Dihydroxyphenyl acetate, (-) Epicatechin (Tsuda et al., 1994), (+) catechin, taxifolin, apigenin, eriodictyol, luteolin and naringenin (Sudjaroen et al., 2005) have been isolated from the seeds of Tamarindus indica, making it a valuable source for recovery of natural antioxidants. But the extraction process of these compounds from the seed is crucial since their application and stability in food system depend on the extraction parameters in use. The aim of extraction is to provide good yield of target substances but most importantly to retain highest quality and most of the activity the seeds actually have.

In the present study, optimisation of extraction parameters for solvent extraction using binary mixture of ethanol and water has been adopted. The two most commonly used optimisation studies are the single-factor experiments and response-surface methodology (RSM). In this study single-factor experiments also known as (One Factor at a Time OFAT study) have been used to optimise the extraction of total phenolics and antioxidants. Correlation analyses on the responses have been studied to judge the suitability of the assays used in the optimisation studies. Solid to solvent ratio, solvent concentration, shaking time and extraction temperature have been investigated as these have shown profound influence on antioxidant property in the previous studies (Pinelo et al., 2005; Yim et al., 2012). The aim of this study has been to optimise the effect of solid to solvent ratio, ethanol concentration, extraction time and extraction temperature for the extraction of phenolic antioxidant from the seeds of Tamarindus indica.

\section{Materials and methods \\ Collection of sample}

Tamarind seeds have been collected from the local markets of Jadavpur near Jadavpur University Campus, a densely populated area of Kolkata, India due to their profound availability. $2 \mathrm{Kg}$ of sample has been procured from fruit sellers for the entire study to maintain uniformity in composition and characteristic properties throughout. Sample collection required very low or negative cost including the transit charges from the collection point to work place.

\section{Preparation of sample}

The whole seeds have been graded \& sorted and cleaned. Further, they have been sun dried for 7 hours for 4 consecutive days bearing an average atmospheric temperature of about $39^{\circ} \mathrm{C}$ to remove the extraneous moisture and stirred occasionally to prevent mold infestation. The seeds have been stored in air-tight containers till they were ground to obtain average sized particle for further investigation (Figure 1).

\section{Chemicals and reagents}

All analytical grade chemicals have been used for experimental purposes and distilled water has been essentially used to make the reagents. The materials which have been used for the purpose of study were procured from Merck (Germany) except for Gallic Acid, from S.d fine chem. Ltd. (Mumbai, India), 2,4,6-Tri(2-pyridyl)-S-triazine (TPTZ), from Himedia (Mumbai, India) and Anthrone Reagent, from Qualigens (Mumbai, India).

\section{Extraction of sample}

Extraction of phenolic antioxidants from the sample has been a three step process, namely extraction in ethanol, defatting and filtering. Figure 2 shows the sequential and progressive steps for obtaining a phenolic antioxidant rich extract from the sample. The dried sample, at first has been subjected to solvent extraction in a temperature-controlled water bath shaker (manufactured by Sicco Instruments Pvt. Ltd., Calcutta, India) at a constant speed of $60 \mathrm{rpm}$ for the various times at variable temperatures. Then the crude extracts have been defatted using hexane as fat solvent in a separating funnel and the ethanolic layer has been collected. This extract has been further filtered using filter paper (Whatman International Ltd., England) of pore size 41 microns and directly used for estimation of phenolic compounds and assessment of antioxidant capacities by various chemical assays. Duplicate runs have been taken for each extraction process and all the analyses have been performed with 3 times reproducibility.

\section{Experimental design}

Single-factor experiments have been used for solvent extraction in the present study. Four factors, namely, solid to liquid ratio (w/v), ethanol concentration, extraction time and temperature have been studied. The levels for each independent variable have been chosen based on two responses of the crude extracts: the total phenolic content (TPC) and total antioxidant content (FRAP). The solid to liquid ratio has been investigated at five levels: 1:10, 1:15, 1:20, 1:25 and1:30. The ethanol concentration has been varied by adjusting the ethanol composition as 25 $\%, 50 \%, 75 \%$ and $100 \%(\mathrm{v} / \mathrm{v})$ in the ethanol-water 
binary mixture. The extraction times studied ranged from 1 -24 hour (1,3,5,9,12,24 hours) and the ranges in temperature variation have been $25^{\circ} \mathrm{C}, 30^{\circ} \mathrm{C}, 40^{\circ} \mathrm{C}, 50^{\circ} \mathrm{C}$.

- Antioxidant components have been extracted using the best solid to solvent ratio selected at the first step, keeping all other parameters constant, i.e $50 \%(\mathrm{v} / \mathrm{v})$ ethanol concentration, $25^{\circ} \mathrm{C}$ temperature and 3 hours of shaking time.

- Using the best solid to liquid ratio selected at first step, phenolic compounds have been extracted at various solvent concentrations keeping the other two parameters constant. The best solvent

\section{Analytical methods \\ Characterisation of sample}

Total calorie value estimation was done using Karas-Simek bomb calorimeter according to the method described by Das and Mondal, 2013. Analysis of total carbohydrate, protein and fat, moisture content (MC) and ash content have been estimated using standard AOAC methods 1975. Volatile solids (VS) and fixed carbon (FC) have been determined according to the standard methods stated by ASTM D3172; Briefly, VS has been estimated by heating the sample for 7 mins in a muffle furnace at $925^{\circ} \mathrm{C}$. FC has been estimated by deducting the sum of moisture content (\%), ash content (\%) and volatile solid (\%) from

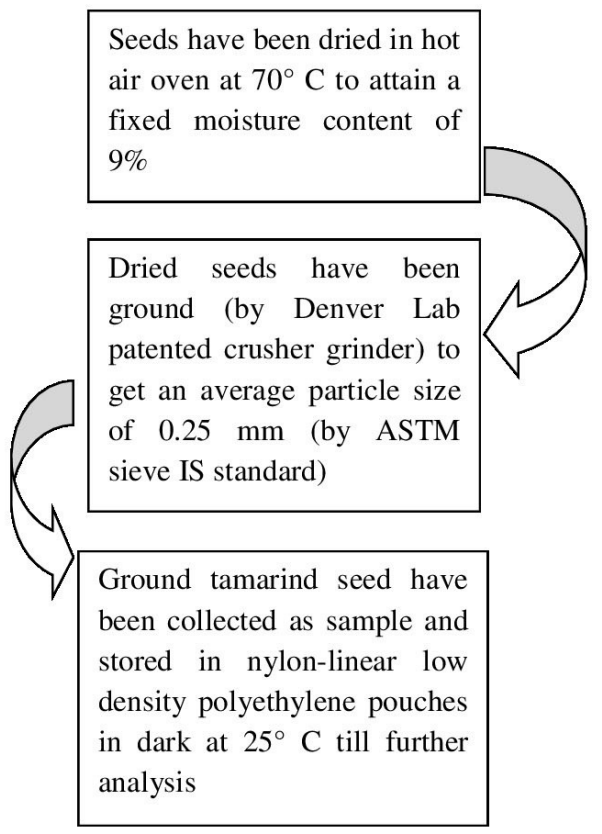

Figure 1. Grinding of whole tamarind seed to homogenous average sized particles

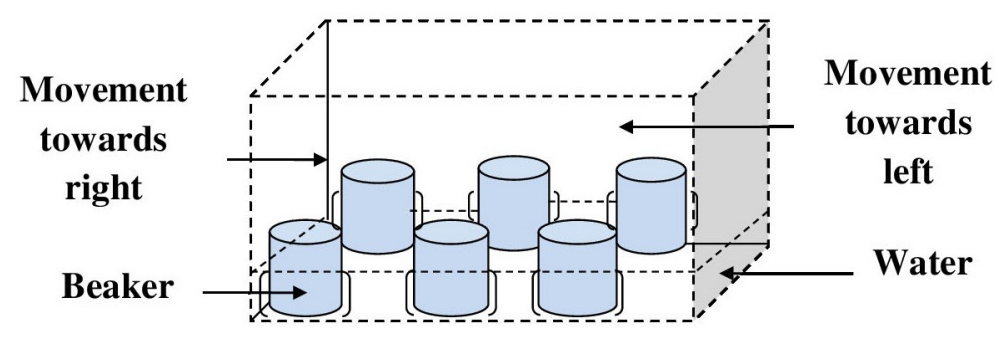

Figure 2 (a) Extraction of phenolic antioxidant by temperature controlled shaker water bath

Figure 2. Extraction of phenolic antioxidants from the sample by a three step process - (a) extraction by heat and agitation (b) de-fatting (c) filtering to obtain phenolic antioxidant rich ethanolic extract.

concentration has been determined at the second step.

- The best extraction time has been selected by considering the best solid to liquid ratio and solvent concentration

- Finally the optimal temperature has been determined.
100(\%). Total solid (\%) has been determined by deducting MC from 100(\%). Bulk density of the sample has been measured in a graduated cylinder (Blake, 1965). pH estimation has been done using single electrode pH meter (Elico LI 120, Hyderabad, India) and solubility test has been done according to the methods described 


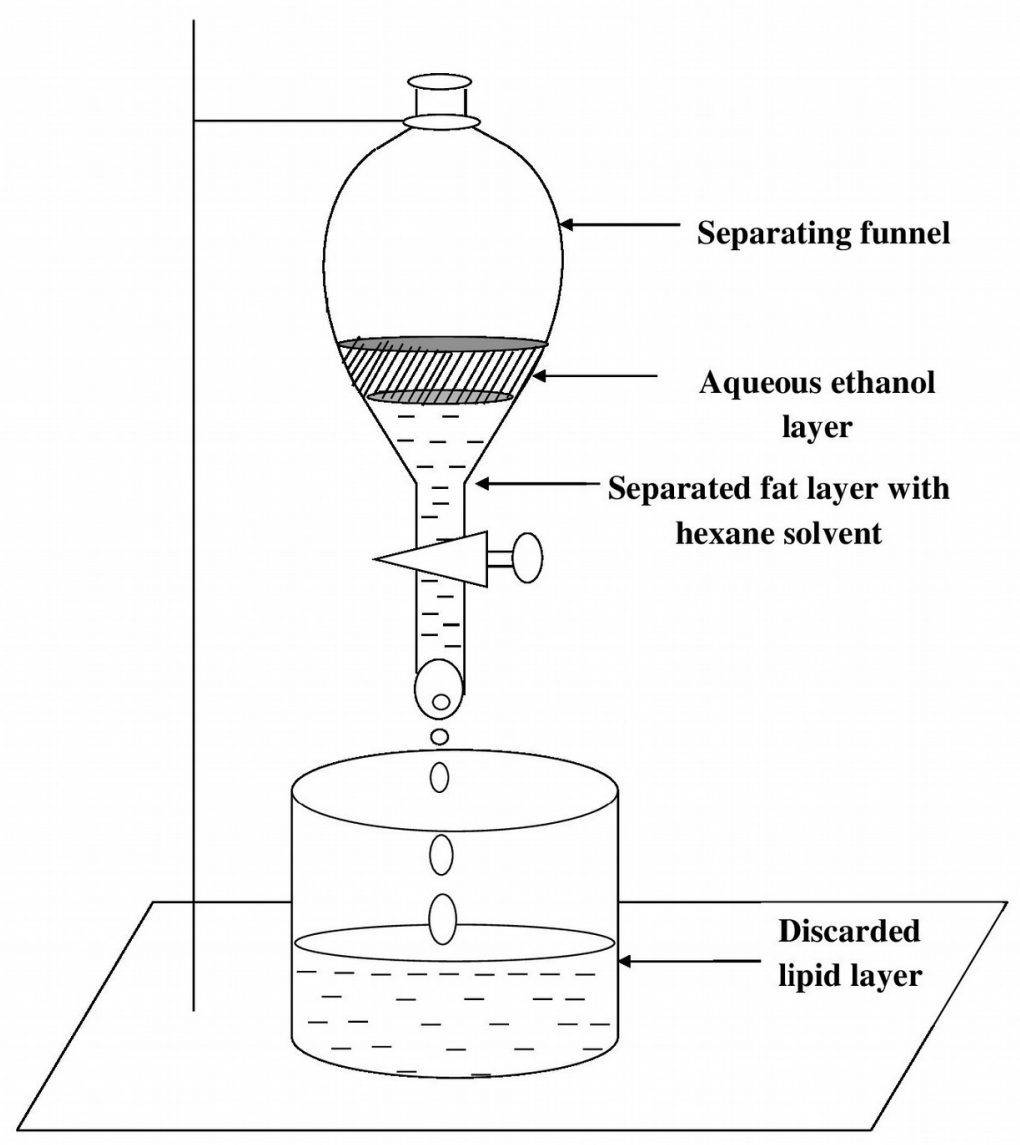

Figure 2 (b) Separation of lipid and ethanol soluble layer in separating funnel

Figure 2 contd. Extraction of phenolic antioxidants from the sample by a three step process - (a) extraction by heat and agitation (b) de-fatting (c) filtering to obtain phenolic antioxidant rich ethanolic extract.

in FSSAI Lab Manual for spices and condiments.

\section{Determination of total polyphenolic content (TPC)}

TPC extracts has been determined by the method described by Malik and Singh, 1980 with some modifications. Briefly, $0.75 \mathrm{ml}$ of different concentrations of the extracts have been taken, to which $3 \mathrm{ml}$ of distilled water and $0.5 \mathrm{ml}$ of Folin- ciocalteu reagent (diluted to $1: 1$ with water) and $1 \mathrm{ml}$ of $20 \% \mathrm{Na}_{2} \mathrm{CO}_{3}$ have been added. After 120 minutes the absorbance has been read by spectrophotometer (Hitachi U- 2000) at 760 $\mathrm{nm}$ wavelength and plotted in a standard calibration curve of Gallic Acid. These results have been expressed as Gallic Acid Equivalents per gram of dry sample.

\section{Determination of total antioxidant content (FRAP assay)}

The FRAP assay has been carried out according to Benzie \& Strain, 1996. Briefly, the FRAP reagent has been prepared from sodium acetate buffer (300 mM, pH 3.6), $10 \mathrm{mM}$ TPTZ solution (dissolved in $40 \mathrm{mM} \mathrm{HCl}$ ) and $20 \mathrm{mM}$
iron(III) chloride solution in a ratio $(\mathrm{v} / \mathrm{v})$ of 10:1:1, respectively. The FRAP reagent has been prepared freshly and warmed to $37^{\circ} \mathrm{C}$ in a water bath before use. $100 \mu \mathrm{l}$ of the sample solution has been added to $3 \mathrm{ml}$ of the freshly prepared FRAP reagent. The absorbance has been measured at 593 nm using spectrophotometer after 4 min and plotted in a standard calibration curve of $\mathrm{FeSO}_{4}$ solution. The results have been expressed as $\mu \mathrm{mol} F \mathrm{Fe}(\mathrm{II}) / \mathrm{g}$ dry sample.

\section{Statistical Analysis}

Results have been expressed as mean \pm standard deviation of triplicate assays and analysed by Microsoft Excel 2007. Pearson correlations between variables have been established using MINITAB (version 17). Significant levels of correlation have been defined using the values $\mathrm{p}<0.05$.

\section{Results and discussions}

Profound nutritional and nutraceutical properties of tamarind seeds have been observed from the selective and mutually exclusive characterization of the sample. Carbohydrate, protein and fat content of the 


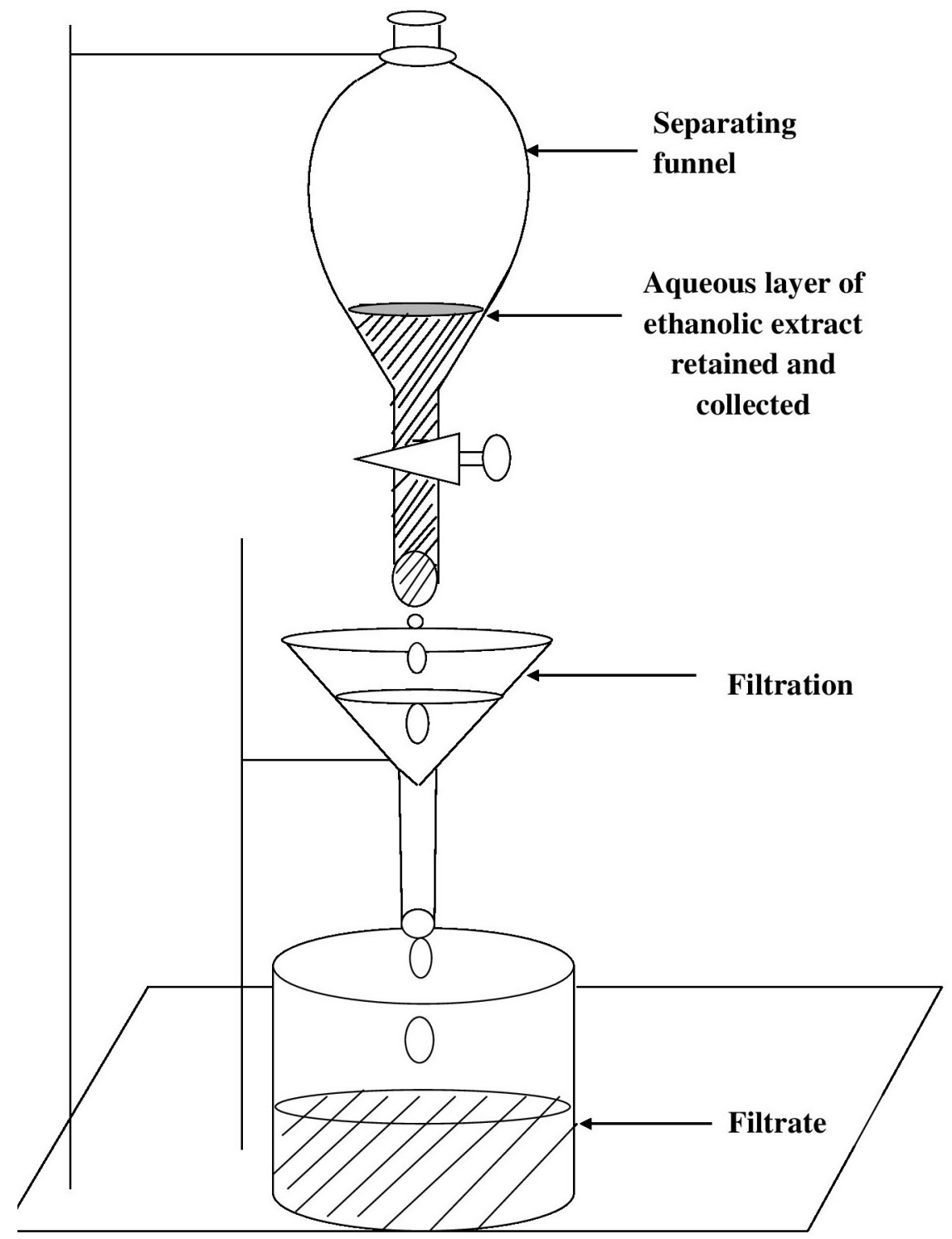

Figure 2(c) Filtration of Ethanol soluble layer to collect crude extract

Figure 2 contd. Extraction of phenolic antioxidants from the sample by a three step process - (a) extraction by heat and agitation (b) de-fatting (c) filtering to obtain phenolic antioxidant rich ethanolic extract.

seed have collectively contributed to the gross calorie content of $4.95 \mathrm{kcal} \mathrm{g}^{-1}$ (Table 1) and it has been observed that tamarind seeds are an important source of phenolic antioxidant. The $\mathrm{pH}$ of the sample has been noted as $5.80 \pm 0.43$ and it has been found to be $70 \%$ soluble in cold water and $89.7 \%$ in $80 \%$ ethanol. In the earlier literatures, researchers reported acetone, methanol, ethanol (Zhou and Yu, 2004; Turkmen et al., 2006) and water (Triantaphyllou, 2001) as the most effective solvents for extraction of antioxidant components. In the present study, the experimental work primarily deals with water and ethanol as aqueous - organic phase for extracting antioxidant components from the sample.

\section{Effect of solid to solvent ratio}

At solid to solvent ratio of 1:20, the highest TPC of $33 \mathrm{mg} \mathrm{GAE} \mathrm{g}^{-1}$ and total antioxidant activity of $210 \mu \mathrm{mol} \mathrm{Fe}$ (II) $\mathrm{g}^{-1}$ have been recorded. Figure 3 shows the successive rise in the phenolic antioxidant content with solid to solvent ratio upto the value of $1: 20$, which justifies the requirement of high solid-tosolvent ratio as a favourable factor in extraction of phenolic compounds. The rate of mass transfer from dissolved particle to liquid solvent depends on various factors; few being -liquid mass transfer coefficient, the total solid - liquid interfacial area and the concentration driving force (Chisti, 2007). The result indicates that a high solid-to-solvent ratio acts as a driving force to increase the concentration gradient, resulting in an increase of diffusion of extractives into the solvent giving a greater extraction. Previous studies also reported larger concentration gradient to be favourable for mass transfer across solid-liquid interface for better antioxidant extraction (Landbo and Meyer, 2001; Al-Farsi and Lee, 2008). 


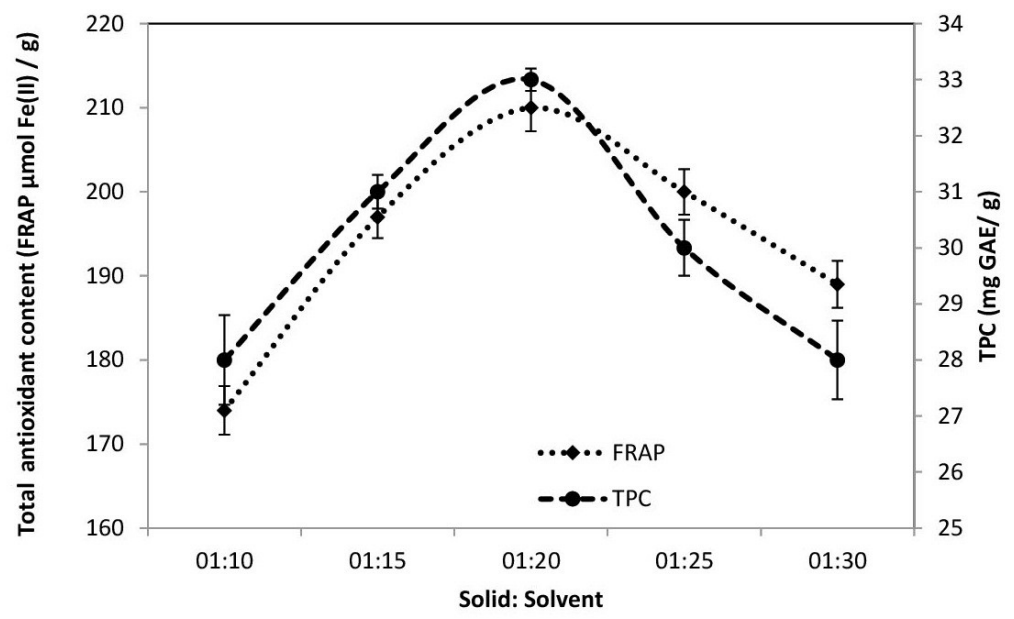

Figure 3 Variation of TPC and Antioxidant activity with varying solid to solvent ratio

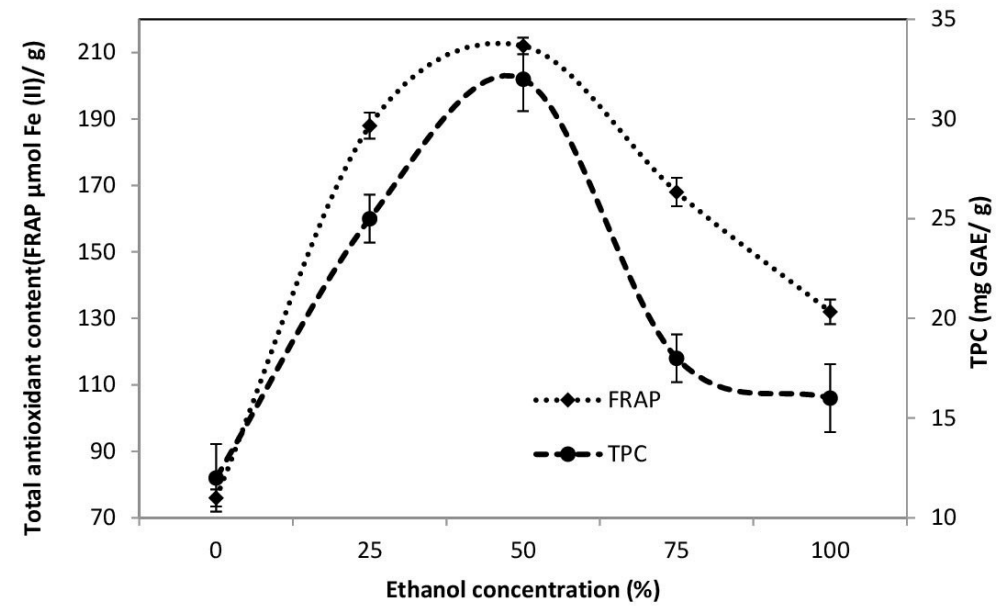

Figure 4 Variation of TPC and Antioxidant activity with varying solvent concentration

However the phenomenon of the static trend in phenolic antioxidant extraction after the ratio of 1:20 can be explained by Fick's Second Law of Diffusion where it is stated that no rise in extraction is possible after an equilibrium is achieved (Zhang et al., 2007), indicating the solid to solvent ratio of 1:20 as the equilibrium point and hence the optimised condition for total phenol and antioxidant extraction from the sample. A significant and strong correlation association $(p<0.05 ; \quad r=0.884)$ between TPC and total antioxidant has been found indicating similar diffusion behaviour of these two variables.

\section{Effect of solvent concentration}

The maximum TPC and antioxidant have been extracted at $50 \%(\mathrm{v} / \mathrm{v})$ ethanol concentration, followed by substantial decrease with further increase in ethanol concentration (Figure 4). The TPC and total antioxidant extracted at this condition have been $32 \mathrm{mg} \mathrm{GAE} \mathrm{g}^{-1}$ and $212 \mu \mathrm{mol}$ Fe (II) g-1 respectively. Alothman et al., 2009 and Chew et al.,2011have reported a solvent concentration of $70 \%$ and $40 \%$ ethanol respectively to be favourable in phenol extraction from plant sources suggesting that binary solvent system favour antioxidant extraction more than single solvent. In the present study $0 \%$ ethanol (100 \% water) and 100\% ethanol extraction proved to be less effective for extraction and suggested that $T$. indica seeds contain diverse phenolic and other antioxidant compounds with different polarity. Thus, it is believed that the effective phenolic compounds in the crude extract, to which the antioxidant capacities are attributed, are intermediate between polar and non-polar. The significant $(\mathrm{p}<0.05)$ and strong $(\mathrm{r}$ $=0.919$ ) correlation between the level of phenolic compounds and antioxidant capacities with regard to ethanol concentration suggest that TPC may be responsible for FRAP capacity of tamarind seed.

\section{Effect of extraction time}

Figure 5 shows the effect of extraction time on phenolic antioxidant extraction. Optimal extraction time has been observed at 3 hours at which point of $32 \mathrm{mg} \mathrm{GAE} \mathrm{g}^{-1}$ of Total Polyphenol and $212 \mu \mathrm{mol} \mathrm{Fe}$ (II) $\mathrm{g}^{-1}$ of total antioxidant have been extracted. This has been followed by successive reduction in both the polyphenol content and antioxidant activity. The hyperbolic trend of polyphenol extraction with increase in extraction time could be well explained by the 


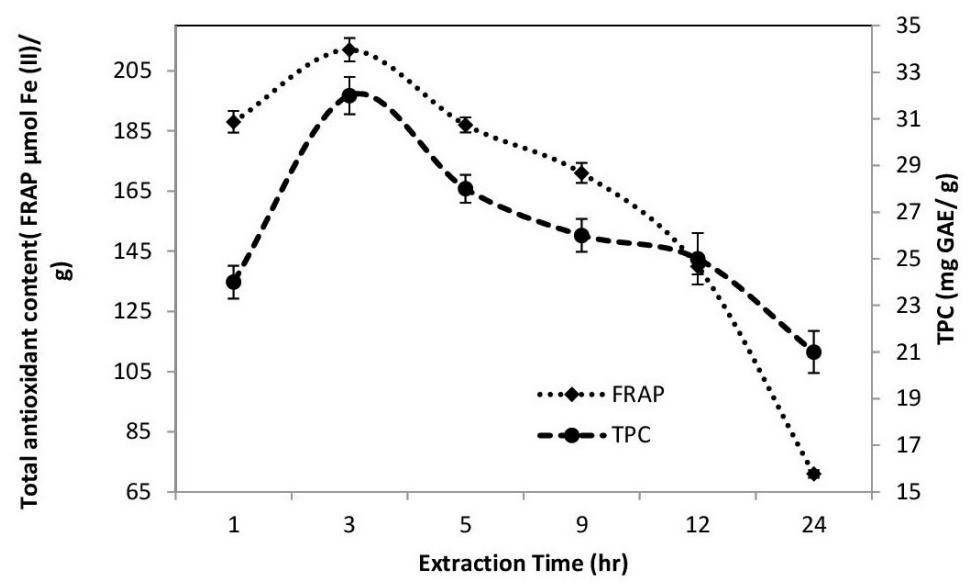

Figure 5 Variation of TPC and Antioxidant activity with varying extraction time

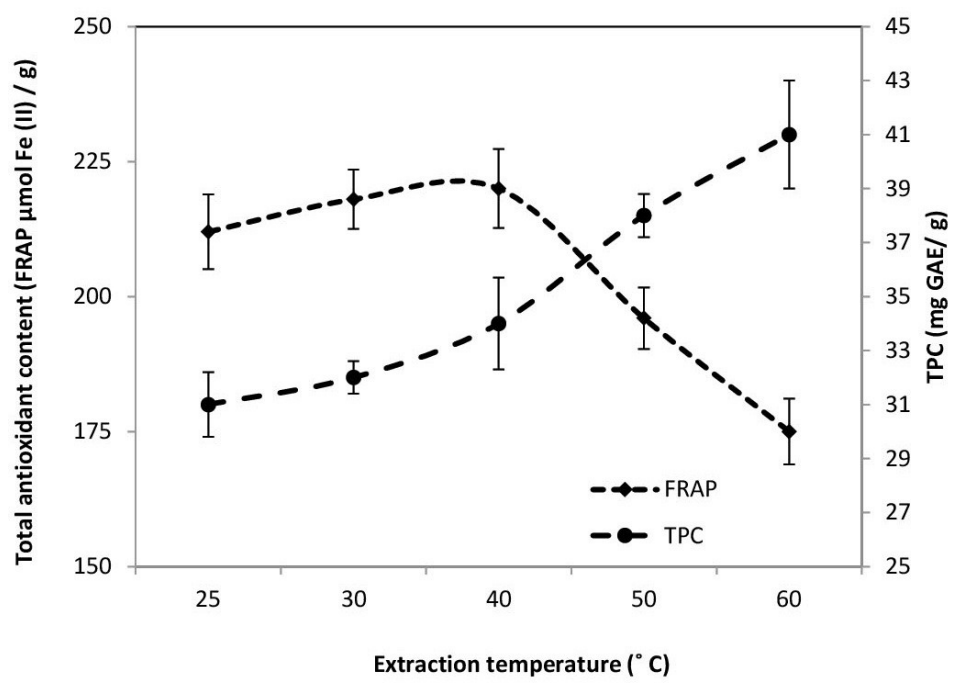

Figure 6 Variation of TPC and Antioxidant activity with varying solid to extraction temperature

Table 1. Characterisation of whole tamarind seed

\begin{tabular}{ll}
\hline Parameters & Amount/100g dried sample \\
\hline Total calorie value & $495 \pm 4.51$ \\
Total Carbohydrate & $55 \pm 1.8 \mathrm{~g}$ \\
Protein & $15.7 \pm 0.97 \mathrm{~g}$ \\
Fat & $5.05 \pm 1.2 \mathrm{~g}$ \\
TPC (water extract) & $987 \pm 2.1 \mathrm{mg} \mathrm{GAE}$ \\
TPC (ethanol extract) & $1887 \pm 3.6 \mathrm{mg} \mathrm{GAE}$ \\
Moisture Content (\%) & $9.44 \pm 0.14$ \\
Total Ash content (\%) & $1.78 \pm 0.03$ \\
Total Solid & $90.56 \pm 0.11$ \\
Volatile Solid & $68.43 \pm 0.36$ \\
Fixed Carbon & $20.35 \pm 0.47$ \\
Bulk density & $0.724 \pm 0.01 \mathrm{gml}^{-1}$ \\
\hline
\end{tabular}

Data shown are the average and standard deviation based on triplicate runs. (mean value \pm standard deviation)

Fick's second law of diffusion, predicting that a final equilibrium between the solute concentrations and in the solvent might be reached after a certain time (Pinelo et al., 2006). A significant $(\mathrm{p}<0.05)$ and positive $(\mathrm{r}=0.824)$ correlation has been found between the levels of phenolic compounds and antioxidant capacities at the different levels of this parameter.

\section{Effect of extraction temperature}

The effect of extraction temperature on the phenolic compounds and antioxidant capacity has been investigated in the temperature range of $25-60^{\circ} \mathrm{C}$. TPC increased with the increase in extraction temperature with a maximum value of $41 \mathrm{mg} \mathrm{GAE} \mathrm{g}^{-1}$ at $60^{\circ} \mathrm{C}$ and antioxidant capacity as a function of extraction temperature showed a parabolic shape with a maximum value of 
$220 \mu \mathrm{mol} F e$ (II) $\mathrm{g}^{-1}$ dried sample at $40^{\circ} \mathrm{C}$ (Figure 6). Hence there is a significant negative correlation $(p<0.05 ; r=-0.909)$ between these variables. The increase in TPC with application of heat may be attributed to the increased in diffusion coefficients solubility of polyphenol content (Al-Farsi \& Lee, 2008). Increased release of polyphenol due to the breakdown of cell wall of plant cells with increase in temperature may be another cause for increase in TPC (Wang et al., 2008). However further investigations by increasing extraction temperature have not been done due to volatile nature of ethanol and its boiling temperature of $78.37^{\circ} \mathrm{C}$. Though the phenolic compounds are thermally stable upto a certain rise in level of temperature, the antioxidant activity has been found to decline with rise in temperature above $40^{\circ} \mathrm{C}$. This may be due to thermal degradation of other antioxidant compounds than polyphenols present in the sample (Chan et al., 2009). Taking into consideration the nutraceutical benefits of antioxidant, $40^{\circ} \mathrm{C}$ has been chosen as the optimised temperature for antioxidant recovery from the sample.

\section{Conclusion}

An effective solvent extraction system for extraction of phenolic antioxidants from seeds of $T$. indica has been determined using single-factor experiments. The optimal solvent extraction conditions have been $50 \%$ ethanol, 3 hours of shaking at $40^{\circ} \mathrm{C}$ in solid to solvent ratio of $1: 20$. Binary solvent mixture has been found to be more effective for phenolic antioxidant extraction as compared to that of mono solvent system. Positive correlation between total antioxidant and TPC recovery have been established in all extraction conditions except for extraction temperature, indicating that antioxidant components except polyphenols degrade at temperatures higher than $40^{\circ} \mathrm{C}$. In the present study, the natural antioxidant extraction parameters have been optimised to make the process more accurate, precise and economic. This study provides constructive information for further optimisation on the extraction of phenolic compounds from $T$. indica using response-surface methodology (RSM). Detailed review indicated that till date none of the literatures reported any information regarding the optimisation of phenolic antioxidant extraction from seeds of $T$. indica. The results provide a reference for future scope of work related to optimisation studies.

\section{Highlights}

a. Single factor optimisation of TPC and Total antioxidant from tamarind seed $T$. indica

b. Characterisation of whole seeds of $T$. indica c. Pearson correlation analysis between TPC and Total antioxidant content at different extraction conditions

\section{Nomenclature}

TPC- Total Polyphenol Content; FRAP- Ferric ion Reducing Antioxidant Power; GAE- Gallic Acid Equivalent.

\section{Authors' contributions}

Both the authors have carried out the research work and participated in manuscript preparation.

\section{Acknowledgement}

This research work has been financially supported by Department of Science and Technology under Ministry of Science and Technology, Government of India in the form of INSPIRE fellowship for doctoral studies.

\section{Competing interests}

The authors declare that they have no competing interests.

\section{References}

Akajiaku, L. O., J. N. Nwosu, N. C. Onuegbu, N. E. Njoku, and C. O. Egbeneke. 2014. Proximate, Mineral and Antinutrient Composition of Processed (Soaked and Roasted) Tamarind (Tamarindus indica) Seed nut. Curr Res Nutr Food Sci 2(3): 136145.doi:10.12944/CRNFSJ.2.3.0510

Al-Farsi, M. A., and C. Y. Lee. 2008. Optimisation of phenolics and dietary fibre extraction from date seeds. Food $\begin{array}{lll}\text { Chem } & 108(3): & 977-985 .\end{array}$ doi:10.1016/j.foodchem.2007.12.009

Alothman, M., R. Bhat, and A. A. Karim. 2009. Antioxidant capacity and phenolic content of selected tropical fruits from Malaysia, extracted with different solvents. Food Chem 115(3): 785-788. doi:10.1016/j.foodchem.2008.12.005

AOAC. 1975. Official Methods of Analysis, $12^{\text {th }}$ edn. Association of Official Analytical Chemists, Washington, DC. 483$484 \mathrm{pp}$.

ASTM D 3172-3175. 1999. Annual Book of ASTM Standards, Section 5 Petroleum Products, Lubricants, and Fossil Fuels, 05.05 Gaseous Fuels, Coal and Coke. American Society for Testing and Materials.

Benzie, I. F. F., and J. J. Strain. 1996. The ferric reducing ability of plasma (FRAP) as a measure of "antioxidant power”: The FRAP assay. Anal Biochem 239: 70-76. doi:10.1006/abio.1996.0292

Bhattacharya, S., S. Bal, R. K. Mukherjee, and S. Bhattacharya. 1993. Some physical and engineering properties of tamarind (Tamarindus indica) seed. $J$ Food Eng 18(1): 77-89. doi:10.1016/02608774(93)90076-V

Blake, G. R. 1965. Bulk density. Methods of Soil Analysis. Part 1. Physical and Mineralogical Properties, Including Statistics of Measurement and Sampling (methods of soil analysis). American Society of Agronomy, Soil Science Society of America, United States. 374-390 pp.

Chan, E. W. C., Y. Y. Lim, S. K. Wong, K. K. Lim, S. P. Tan, F. S. Lianto, and M.Y. Yong. 2009. Effects of different drying methods on the antioxidant properties of leaves and tea of ginger species. Food Chem 113(1): 166-172. doi:10.1016/j.foodchem.2008.07.090 
Chew, K. K., M. Z. Khoo, S. Y. Ng, Y. Y.Thoo, W. M. Wan Aida, and C. W. Ho. 2011.Effect of ethanol concentration, extraction time and extraction temperature on the recovery of phenolic compounds and antioxidant capacity of Orthosiphon stamineus extracts. Int Food Res J 18(4): 1427-1435.

Chisti, Y. 2007. Mass transfer. In: Kirk-Othmer encyclopedia of chemical technology online. John Wiley and Sons, Inc., _New Jersey, United States. p. 1-79.

Das, A. and C. Mondal. 2013. Catalytic effect of tungsten on anaerobic digestion process for biogas production from fruit and vegetable wastes. Int. j. eng. sci. technol 2(4): 216-22.

FSSAI. 2015. Manual of Methods of Analysis of Foods Spices and Condiments. Food safety and standards authority of India, Ministry of Health and Family Welfare, Government of India, New Delhi, India. 15- 16 pp. available

http://www.fssai.gov.in/Portals/0/Pdf/Draft_Manuals/S PICES_AND_CONDIMENTS.pdf

Karre, L., K. Lopez, and K. J. Getty. 2013. Natural antioxidants in meat and poultry products. Meat Sci 94(2): 220-227. doi:10.1016/j.meatsci.2013.01.007

Kumar, C. S., and S. Bhattacharya. 2008. Tamarind seed: properties, processing and utilization. Crit. Rev. Food Sci. Nutr 48(1): 1-20.doi: 10.1080/10408390600948600

Landbo, A. K., and A. S. Meyer. 2001. Enzyme-assisted extraction of antioxidative phenols from black currant juice press residues (Ribes nigrum). J. Agric. Food Chem 49: 3169-3177. doi:10.1021/jf001443p

Li, J. H., J. Miao, J. L. Wu, S. F. Chen and Q.Q. Zhang. 2014. Preparation and characterization of active gelatinbased films incorporated with natural antioxidants. Food Hydrocoll 37: 166-173. doi:10.1016/j.foodhyd.2013.10.015

Ortiz, J., J. P. Vivanco, V. Quitral, M. A. Larraín, G. Concha, and S. P. Aubourg. 2012. Changes in freshness during frozen storage of farmed coho salmon: effect of replacement of synthetic antioxidants by natural ones in fish feeds. N. Am. J. Aquacult 74(2): 224-229. doi: 10.1080/15222055.2012.675994

Malik, C. P., and M. B. Singh, 1980. Plant enzymology and histo-enzymology. Kalyani Publishers, New Delhi, India. $278 \mathrm{pp}$.

Pinelo, M., M. Rubilar, M. Jerez, J. Sineiro, and M. J. Nüňez. 2005. Effect of solvent, temperature, and solvent-tosolid ratio on the total phenolic content and antiradical activity of extracts from different components of grape pomace. J. Agric. Food Chem 53(6): 2111-2117. doi: 10.1021/jf0488110
Pinelo, M., J. Sineiro and M. J. Nüňez. 2006. Mass J Food Eng 77(1): 57-63. doi:10.1016/j.jfoodeng.2005.06.021

Reis, P. M. C. L., C. Dariva, G. Ã. B Vieira and H. Hense. 2016. Extraction and evaluation of antioxidant potential of the extracts obtained from tamarind seeds (Tamarindus indica), sweet variety. J Food Eng 173: 116-123. doi:10.1016/j.jfoodeng.2015.11.001

Spices Board India, Ministry of Commerce \& Industry, Government of India, http://indianspices.com/sites/default/files/Major-spicwise-area-and-production-web-2015.pdf

Sudjaroen, Y., R. Haubner, G. Würtele, W. E. Hull, G. Erben, B. Spiegelhalder, S. Changbumrung, H. Bartsch, and R. W. Owen. 2005. Isolation and structure elucidation of phenolic antioxidants from Tamarind (Tamarindus indica L.) seeds and pericarp. Food Chem. Toxicol 43(11): 1673-1682. doi:10.1016/j.fct.2005.05.013

Triantaphyllou, G. B. D. B. K. 2001. Antioxidative properties of water extracts obtained from herbs of the species Lamiaceae. Int I Food Sci Nutr 52(4): 313-317. doi:10.1080/09637480120057512

Tsuda, T., M. Watanabe, K. Ohshima, A. Yamamoto, S. Kawakishi, and T. Osawa. 1994. Antioxidative components isolated from the seed of tamarind (Tamarindus indica L.). J. Agric. Food Chem 42(12), 2671-2674.doi: 10.1021/jf00048a004

Turkmen, N., F. Sari, and Y. S. Velioglu. 2006. Effects of extraction solvents on concentration and antioxidant activity of black and black mate tea polyphenols determined by ferrous tartrate and Folin- Ciocalteu methods. Food Chem 99(4): 835-841. doi:10.1016/j.foodchem.2005.08.034

Wang, J., B. Sun, Y. Cao, Y. Tian, and X. Li. 2008. Optimisation of ultrasound-assisted extraction of phenolic compounds from wheat bran. Food Chem 106(2): 804810. doi:10.1016/j.foodchem.2007.06.062

Yim, H. S., F. Y. Chye, S. M. Koo, P. Matanjun, S. E. How, and C. W. Ho. 2012. Optimisation of extraction time and temperature for antioxidant activity of edible wild mushroom, Pleurotus porrigens. Food Bioprod Process 90(2): 235-242. doi:10.1016/j.fbp.2011.04.001

Zhang, Z. S., D. Li, L. J. Wang, N. Ozkan, X. D. Chen, Z. H. Mao, H. Z. Yang. 2007. Optimisation of ethanol-water extraction of lignans from flaxseed. Sep Purif Technol 57(1): 17-24. doi:10.1016/j.seppur.2007.03.006

Zhou, K., and L. Yu. 2004. Effects of extraction solvent on wheat bran antioxidant activity estimation. LWT-Food Sci Technol 37(7): 717-721. doi:10.1016/j.lwt.2004.02.008.

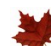

